\title{
Cost benefit analysis of energy efficient family houses
}

\author{
H. Krstić ${ }^{1} \&$ K. $\check{C C u l o}^{2}$ \\ ${ }^{1}$ University of Osijek, Faculty of Civil Engineering, Organization, \\ Technology and Management Department, Croatia \\ ${ }^{2}$ University of Osijek, Faculty of Civil Engineering, \\ Organization, Technology and Management Department, Croatia
}

\begin{abstract}
Buildings have a significant environmental impact. It is estimated that buildings are responsible for 40 per cent of the total energy consumption in the European Union. In this respect it should be taken into account that the major demand for housing and primary market area for eco-efficient construction is single-family housing. A practical goal of a low energy building is to try to achieve the highest energy efficiency with the lowest possible need for energy within the economic limits of reason. In the last 15-20 years, a number of projects have been carried out aiming at energy-efficient and environmentally friendly housing. Also, technological possibilities to reduce a building's energy consumption have been available for a long time. However, despite the existing vast amount of information, no clear market change has happened. Therefore, special measures are needed to promote commercialization. They should target both, the demand and supply sides. On the demand side there is a need for pilot projects and case studies that should demonstrate that the higher initial construction costs of an energy efficient house can be offset in a short period of time by energy consumption savings. To these end, cost-benefit analyses are needed, that would take into account, beside the direct financial results, also the impact on the environment. This article considers a range of variables that should be included in such analyses. The article is part of a scientific project titled Evaluation of the correlation between investment projects and the environment financed by the Ministry of Science, Education and Sport of the Republic of Croatia.
\end{abstract}

Keywords: energy efficiency, family housing, cost-benefit analysis. 


\section{Challenges of energy efficient housing}

Today's world is highly dependent on carbon fuels the reserves of which are being rapidly depleted. Consequently, the world economy is facing a problem of energy shortage and is trying to find optimal ways and means of energy saving in order to continue its growth. The same is true for ordinary citizens who have to cope with the ever increasing cost of energy consumption. The overall goal is to use the energy in a more efficient way and at the same time not endangering the environment. Sustainable development and development of the knowledge society will affect the production, supply chains and delivery modes of buildings. The possible solutions can be the use of renewable energy sources (water, biomass, solar energy and wind), a more efficient energy distribution producing less waste, and energy efficient buildings that would reduce the energy consumption to a minimum.

Buildings and particularly their use have a significant environmental impact and thus more sustainable solutions are gravely needed. It is estimated that buildings are responsible for 40 per cent of the total European Union energy consumption. Therefore, there is a need for energy efficient buildings. However, the definition of energy efficiency in buildings is somewhat ambiguous. Energy efficient buildings and low energy buildings are frequently used as synonyms. The scope of an energy efficient building is to achieve comfortable, healthy and safe indoor climate. The major characteristics of such buildings are (i) the use of building materials with no detrimental impact on the environment, (ii) the low energy consumption and (iii) rationale disposal of the rubble and waste produced during building construction and/or demolition.

In this respect, a special focus should be on housing, which represents a major portion of energy consumption in buildings. In the perspective of an individual, housing is a topic that has an effect on everybody. The purchase of a house is in most cases the biggest investment during the lifetime. Taken this, single-family houses are something to put emphasis on when promoting energy efficiency.

Highly efficient buildings with significantly lower energy consumption are achievable through good design practices and effective use of energy efficient technologies. In an ideal case, buildings can even act as producers rather than consumers of energy. When planning an energy efficient single-family house the main systems and solutions should be chosen at an initial stage. Additionally, the house should be seen as a whole, not something constructed of different parts.

Generally, there are two sets of measures aiming at energy efficient housing: the first set includes simple measures that are mainly defined by the law and they require small investments and quick return and the second one which provides measures to be chosen and implemented by investors and which can increase the investment up to $20 \%$ with a longer period of return. The first set includes the measures such as a proper selection of building site, building orientation and shape, use of energy efficient entrances, windows, household appliances and lighting as well as use of high quality thermal insulation.

The second set includes measures such as a proper choice of building material and systems, use of energy efficient HVAC systems, generation and 
accumulation of alternative energy (extracting energy with heat pumps or recovering heat from exhaust air) and generating energy from renewable sources.

In the last two decades, a number of projects have been carried out aiming at energy-efficient and environmentally friendly housing. There is a wide range of technologies and concepts that have been tested in monitoring projects. Technological possibilities to reduce a building's energy consumption have been available for a long time and the costs of energy efficiency have been proved to be almost negligible. An energy efficient house is a financially sound investment, but also a healthy living environment. Nevertheless, the market interest in energy efficient houses is still low. One of the reasons may be that the general public and end users are not aware of the benefits and therefore there is a lack of demand. To these ends, it is important that the end users, house owners, should be informed and educated, but there are also other stakeholders, like contractors, equipment suppliers and government authorities, who should be also informed and educated, because all of them are equally important, fig. 1 .

So far, contractors, architects and manufacturers take most responsibilities for successful design and construction of energy efficient houses. For the time being, they are the most influential participants in the process and as long as the other stakeholders do not take more active role and create an receptive environment, no significant progress can be expected.

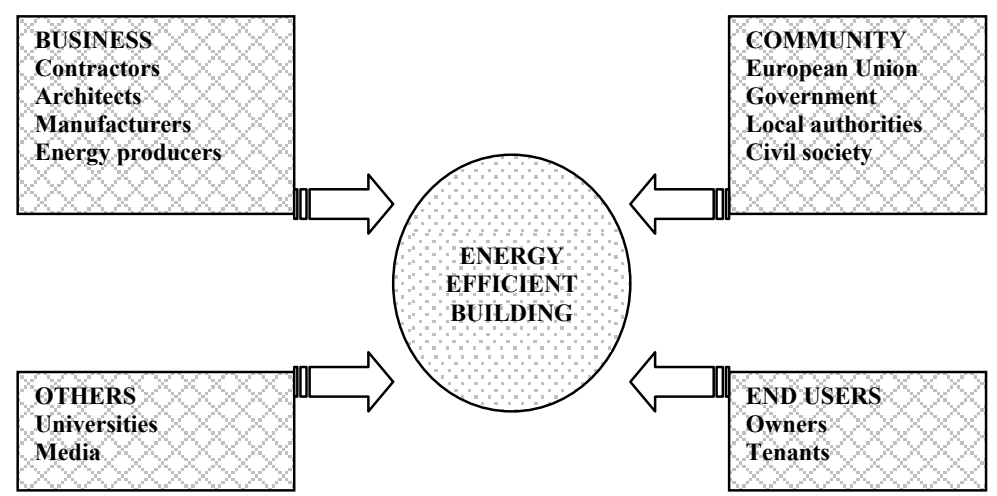

Figure 1: Key actor groups in energy efficient housing.

In this respect, it is interseting to note that in some european countries, the energy producers have undertaken initial steps towards energy efficient buildings, i.e. a steps related to consumption control. The reason is very simple they are forced to reduce the ever growing discrepancy between the energy generation capacity and the forecasted demand. 
Contractors and manufacturers are facing a variety of risks associated with the energy efficient builinds, such as financial risks, use of new and not yet proven materials and technologies, higher construction costs compared with traditional buildings, a longer time needed for construction, increased cost of staff education and training, unknown market, lack of demand, and additional money needed for market research.

\section{Energy efficient housing projects in Croatia}

Interes for energy efficient housing in Croatia at the moment is far from desired. There is a very high demand in the housing market and contarctors are primarily interested in quick return and low cost construction. They are not interested in and do not have incentives for investment into and development of new technologies. And above all, there is no demand for such kind of buildings. Therefore, the government has taken the initiative in this field.

United Nations Development Program (UNDP) together with the Ministry of Economy, Labor and Entrepreneurship (MELE) has started a project titled "Energy Efficiency in Croatia" aiming at increasing awareness of citizens of rationale energy consumption and promotion of economically rationale and energy efficient (EE) technologies, proper materials and available services in Croatia. The promotion of energy efficiency has been supported by the government and legislative through the following activities:

- The Energy Law (special sections on energy efficiency and renewable energy sources);

- The Energy Development Strategy, aiming at increasing the energy efficiency;

- The National Programs of Energy Efficiency, adopted by the government; and

- Master Plan of Energy Efficiency, being now under the process of public consultations.

In addition, Fond for Environment Protection and Energy Efficiency has been established in order to ensure additional resources for financing programs, projects and other activities related to preservation, sustainable use, protection and development of environment.

The "Energy Efficiency in Croatia" project started in 2005 and will be implemented in four years. It is in line with Directive 2006/32/EC which aims at reducing the energy consumption by $9 \%$ in the ninth year of implementation. Project activities are focused on end users in the household sector and house owners, facility managers, designers, architects, contractors, schools, nongovernmental organizations, and media.

Several other energy efficiency related projects have been under implementation in Croatia. The one titled "Croatian Solar House" is a national scientific project prepared and implemented by the Center for Renewable Energy Sources (CRES). It will receive all the energy needed for heating, ventilation, cooling, hot water and light from the solar energy only. The project includes construction of a sample house - a living laboratory - with an initial energy 
standard of a passive house. Once the house is completed, during the first phase, there will be no tenants living in it, and simulations will be carried out, resembling a real situation. The simulation will enable study of all relevant elements as well as of the whole system, but also to discover possible errors in the design and functioning. During the second research phase, the house will be inhabited with a group of researchers who will continue the research in the real situation as well as the changes in the system caused by living people.

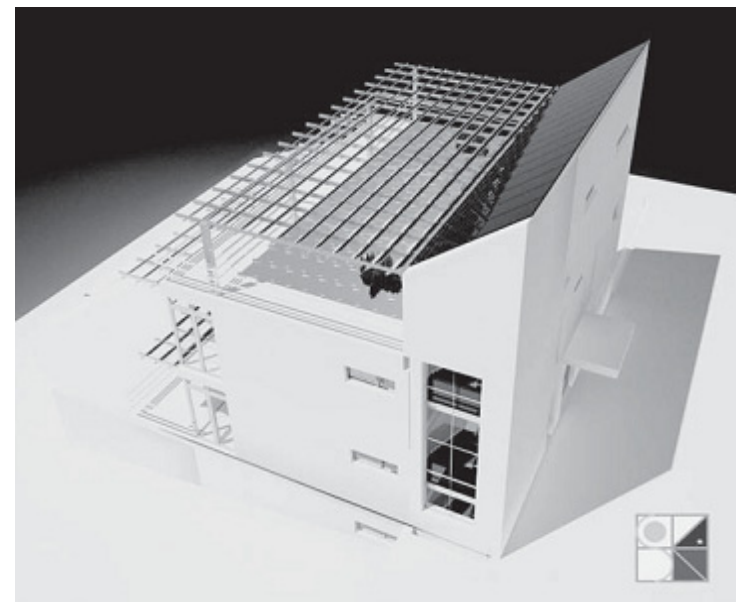

Figure 2: $\quad$ Croatian Sun House M4.

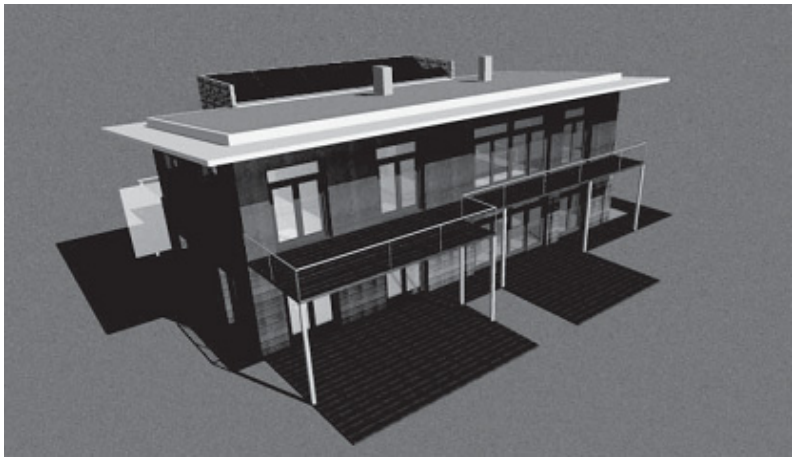

Figure 3: $\quad$ First Croatian Passive Timber House ČV1.

There are several pilot low energy houses in Croatia, one called M4, fig. 2 [3] and the other CV1, fig. 3 [3], both designed for energy consumption for heating of only $15 \mathrm{KWh}$ per one square meter. The house CV1 is a wooden passive house and the house M1 is made of porous concrete. They are so called "houses with no heating" or "houses of warm comfort without heating" or "one liter houses", because the energy consumption for heating is equal to one liter of fuel per one square meter. 
The first passive house in Croatia was constructed in Brestovje near the capitol Zagreb. The total investment, together with the land, amounted to about 80,000 euro for 100 sq. meters of first floor plus 100 sq. meters in the second floor. The investment was by $20 \%$ higher than the investment in the standard house of equal size. However, the savings after the investment recovery period, estimated at 8 years, will be remarkable. Recurrent energy costs for the whole house, including heating, cooling, hot water and appliances, amount to about 300 euro per year or 25 euro per month.

In Croatia, there is also a so called "null house", i.e. a house which not only covers its own energy needs, but generates an energy surplus that can be delivered into the energy distribution system. It is located in Zagreb as part of the project "Spansko Solar Roof". Thanks to its 10 sq. meters of roof mounted solar collectors, the house produces more energy than it consumes.

Despite of these, well prepared and successfully implemented project, there is an obvious lack of interest in the housing market in Croatia. So far, except simple cost recovery appraisals, no comprehensive research and comparisons based on cost benefit analysis have been conducted in Croatia to show the benefits of energy efficient houses.

\section{Public awareness building and marketing campaign}

As mentioned, public awareness of its benefits is one of the key factors in promoting and implementation of energy efficiency and low energy buildings. On the other hand, there should be a well targeted marketing of related technologies and products. The public awareness and marketing campaign should be oriented towards two groups, explaining particular benefits to each of the groups, as for example:

Benefits to contractors and manufacturers:

- expected increase in demand for energy efficient technologies and products, thus the first-comers will most probably take the greater piece of the cake;

- creation of an image of "ecology responsive" company; and

- Market share widening.

Benefits to end users:

- definite savings in energy consumption;

- reduced damage to the environment;

- increased comfort; and

- better health and enhanced safety.

If a marketing of energy efficiency technologies and products tends to be successful, it is important for the marketing manager to:

- know well the up-to-date construction $\mathrm{n}$ practices and methods in the country;

- $\quad$ analyze demand and supply market;

- prepare a cost benefit analysis as to show the benefits to potential investors; 
- make an accurate forecast of energy prices;

- $\quad$ ascertain availability of technologies and products; and

- gather relevant information on the age, education level, gender and investment capacity of potential customers.

There are several approaches that, when properly implemented, can promise a successful marketing, such as to: (a) make potential users aware of the benefits of energy efficient houses; (b) explain how the increased investment cost can be recovered by savings in energy consumption; (c) inform potential customers on construction methods and technologies, using pilot projects and site visits; (d) educate general public through leaflets, brochures, promotion CDs, seminars, and alike; (e) provide guarantees as to the maximum level of energy costs; and (f) make available attractive bank loans for investment financing.

However, in order to be convincing, marketing of energy efficient technologies and products for housing should be based on a cost benefit analysis, which is seldom the case.

\section{Cost benefit analysis}

Cost benefit analysis is a means for economic and financial justification of an investment, in this case of an investment in a low energy house. Such an analysis should present evidence that a planned energy efficient house will in the long run, not only result in considerable savings that will offset the higher investment cost compared to traditional house, but will also have a positive impact on the environment. The proven direct savings in energy consumption and costs, might be a good case for lending and financing institutions. It can be expected that the banks will be able and willing to offer favorable loans for low energy houses, based on cost benefit analysis as well as on targeted support by the government.

Generally, a cost benefit analysis should take into account the following data related to a particular country: Kyoto Protocol requirements; the legal and regulatory framework related to energy and environment; the level of household energy consumption in total and average; housing construction market; and demand and supply market for energy efficient technologies and products.

The following elements have to be identified and analyzed:

- construction costs, which are usually higher than those in traditional house construction;

- maintenance and repair costs;

- house life cycle period;

- cost of house demolition and rubble disposal

- $\quad$ savings in energy consumption;

- $\quad$ energy efficiency of appliances used in households;

- local and global impact on the environment;

- reduction of gas emission into atmosphere;

- choice of the discount rate for calculation of the NPV;

- relative comfort of house users;

- health issues; 
- impact on the environment through reduction of gas emission, and less energy generation and transmission; etc.

Probably the most difficult part of the analysis is the question how would future tenants or house owners react and behave in a low energy house, because it requires a somehow different way of life. Every cost benefit analysis must have a sensitivity analysis to check the results against changes of important variables, such as how the changes in costs would impact the economic justification of the project. In addition, it is recommendable to present the strength and weaknesses of either alternatives, i.e. traditional and low energy house, in a form of SWOT analysis.

From the experience gained in some advanced countries, the costs and benefits of energy efficient houses, compared with traditional houses, can be illustrated by some comparative data (NPV) as below:

- initial investment is higher by $0-20 \%$,

- total life cycle costs are lower by $10-30 \%$,

- total return during the life cycle is higher by $30-50 \%$,

- remaining value at the end of life cycle is higher by $10-30 \%$

Table 1. [1] Illustrates in more detail the above general comparison data.

Table 1: Direct benefits of eco-efficiency for a home builder.

\begin{tabular}{|c|c|c|}
\hline $\begin{array}{l}\text { Location: Tuusniemi, Finland } \\
\text { Reference period: } 20 \text { years } \\
\text { Real interest rate: } 2,0 \% \\
\text { Cost properties }\end{array}$ & $\begin{array}{c}\text { Typical house } \\
150,0 \mathrm{~m}^{2} \\
€ / \mathrm{m}^{2}\end{array}$ & $\begin{array}{c}\text { Eco-efficient house } \\
150,0 \mathrm{~m}^{2} \\
€ / \mathrm{m}^{2}\end{array}$ \\
\hline Acquisition costs (Aqi) & $1.370,00$ & $1.405,00$ \\
\hline $\begin{array}{l}\text { Financing cost: loan for } 60 \% \text { for acquisition } \\
\text { cost } / 15 \text { years }\end{array}$ & 140,00 & 145,00 \\
\hline $\begin{array}{l}\text { Maintenance cost (actions defined in house } \\
\text { manual) } \\
\text { Operating cost }\end{array}$ & $\begin{array}{l}100,00 \\
355,00\end{array}$ & $\begin{array}{c}90,00 \\
180,00\end{array}$ \\
\hline Heating energy & 110,00 & 35,00 \\
\hline Electrical energy & 40,00 & 35,00 \\
\hline $\begin{array}{r}\text { Other operating cost } \\
\text { Adantahilitu }\end{array}$ & 80,00 & 40,00 \\
\hline $\begin{array}{r}\text { Risk cost; damages that cannot be anticipated } \\
\text { Development cost; for adaptability }\end{array}$ & $\begin{array}{l}40,00 \\
50,00\end{array}$ & $\begin{array}{l}40,00 \\
20,00 \\
\end{array}$ \\
\hline Life-cycle cost LCC & $1.965,00$ & $1.820,00$ \\
\hline Life-cycle income LCI & $2.040,00$ & $2.040,00$ \\
\hline Life-cycle economy LCE $=$ LCI-LCC & 75,00 & 220,00 \\
\hline Resale value RV & $1.000,00$ & $1.200,00$ \\
\hline $\begin{array}{l}\text { Life-cycle profit } \\
\mathrm{LCP}=(\mathrm{LCE}+\mathrm{RV}) /(\mathrm{Aq} \times \mathrm{t})\end{array}$ & $3,90 \%$ & $5,10 \%$ \\
\hline
\end{tabular}




\section{Conclusions}

Despite the numerous problems and obstacles, the energy efficient buildings, and especially, low energy family houses, will certainly find their place in the market and for many reasons. On one hand, there is ever increasing awareness of damages to the environment caused by the uncontrolled use of carbon fuels and on the other hand the threat of energy shortages once the sources of carbon fuels have been depleted.

Energy efficient family houses, in addition to the lower energy consumption for heating and cooling, compared to traditional houses, offer healthier and more comfortable living environment. Besides, there are considerable cost savings in the long run that offset the higher initial investment.

In order for the concept to be accepted in the housing market, there is a need for public awareness building and marketing campaign as well as for education of all stakeholders. Cost benefit analyses should prove the justification and viability of the concept.

\section{References}

[1] M. Halme et al [4] Business from Sustainability, Drivers for Energy Efficient Housing. Finland: VTT Technical Research Centre of Finland (2005)

[2] D.W Pearce and J.W. Warford, World Without End: Economics, Environment, and Sustainable Development. Oxford: Oxford University Press (1993)

[3] XIV. Forum - Energy Day in Croatia, Zagreb: Croatian Energy Society, (2005), $117-126$

[4] XV. Forum - Energy Day in Croatia, Zagreb: Croatian Energy Society, (2006), $153-156$

[5] Handbook on Economic Analysis of Investment Operations, Washington: World Bank (1996)

[6] UNDP Projektni ured, Projekt poticanja energetske učinkovitosti u Hrvatskoj, www.energetska-efikasnost.undp.hr/show.jsp

[7] Web portal Gradimo, www.gradimo.hr/4539.aspx

[8] Web portal Net, www.net.hr/alternativa/page/2006/05/10/0005006.html

[9] Web portal Korak, www.korak.com.hr/ispis_sos_vise.php?id_sos=184

[10] The American Building Performance Rating, www.natresnet.org/rater/ business/ services.htm 